\title{
Analysis and Evaluation of Operational Status of Vertical Cylindrical Furnace
}

\author{
Dong Sun ${ }^{1}$, Guodong Feng ${ }^{1}$, Weibo Zheng ${ }^{1}$, Lu Fan $^{1}$, \\ Xiaofeng $\mathrm{Hu}^{1}$ \\ Shengli Oil Field Technology Testing Center, \\ Dongying, China, 257000
}

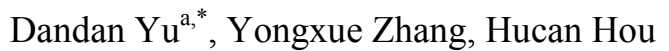 \\ College of Machinery and Transportation Engineering, \\ China University of Petroleum, \\ Beijing, China, 102200 \\ ayudandan613@163.com
}

\author{
Menglong Li \\ College of Petroleum Engineering, \\ China University of Petroleum, \\ Beijing, China, 102200
}

\begin{abstract}
Vertical cylindrical furnace is the key equipment and the main structural unit in petroleum industry, so it is very significant to analyze and evaluate the operational status of vertical cylindrical furnace. In this paper, a vertical cylindrical furnace in Shengli Oilfield was taken as the research object, and the impact of air excess ratio and flue gas temperature on it was analyzed by the way of simulation. The conclusion was made that when the air excess ratio was 1.05 , flue gas temperature was $130^{\circ} \mathrm{C}$, emissivity was 0.4 , the furnace reached the optimum conditions.
\end{abstract}

Keywords-vertical cylindrical furnace; numerical simulation; thermal efficiency; $\mathrm{NO}_{x}$ emissions.

\section{INTRODUCTION}

In the field of oil and gas gathering systems, vertical cylinder furnace is widely applied in combination stations as a key equipment because of the advantages of uniform heating and safe. Its operational state would directly affect the efficient, safe and stable operation of oil production. Now, there are higher requirements for the safe and economic operation of tube furnace, as the increasingly exploitation quantity. According to the statistics, in petroleum industry, the fuel consumption costs of tube furnace can be more than $5 \%$ of the total value of the heating medium, which showed that heating furnace is a developing facility which need high investment and cost.[1] Therefore, it is very significant to analyze and evaluate the operational status of furnace.

Thermal efficiency of furnace is relatively high, since this kind of boiler burns oil or gas. Generally, the rated thermal efficiency could reach $88 \% \sim 90 \%$. But in the actual running time, many furnaces can not reach the standard. In general, under the normal operational status, main factors which impact the thermal efficiency are flue gas loss and heat dissipation loss. According to the on-site test data, exhaust gas loss, as the most sensitive factor, is accounted for more than $80 \%$ of the total energy loss. Therefore, reducing flue gas loss is the most important way to improve the thermal efficiency of furnace. At the same time, in terms of energy conservation and environmental protection, it is very significant to focus on the $\mathrm{NO}_{\mathrm{x}}$ emissions.

The main factors influencing the exhaust gas loss are flue gas temperature and air excess ratio. By calculation, thermal efficiency of furnace would be reduced $1 \%$ while air excess ratio increased $10 \%$ or flue gas temperature increased $20{ }^{\circ} \mathrm{C}$. Table 1 illustrates the test results of 4 tube furnace. It can be seen that the thermal efficiency of furnaces which have excessive air excess ratio and flue gas temperature is lower.

For a long time, control of air intake of tube furnace used in oilfield was only to rely on workers' experience to control manually rather than automatic control, and thermal efficiency also could not be real-time monitoring, which often appeared the situation that excess air ratio was high, resulting high gas temperature, fluctuant thermal efficiency and high heat loss. Low thermal efficiency of furnace caused pollutant emissions, such as $\mathrm{NO}_{\mathrm{x}}$, discharged a lot, which is not conducive to energy-saving and emissions reduction.

With the rapid development of computer technique, numerical simulation has become an effective means to research complex combustion process. It can present the detailed information of the whole combustion process, so as to provide the theory basis for the design and transformation of furnace.[2] In this paper, numerical simulation method was employed, and the impact of air excess ratio, flue gas temperature and $\mathrm{NO}_{\mathrm{x}}$ emissions laws, etc. on the thermal efficiency of furnace was analyzed. 
TABLE 1. MEASURING RESULTS OF TUBE FURNACE

\begin{tabular}{ccccc}
\hline NO. & $3-1 \#$ & $3-2 \#$ & $5-2 \#$ & $3-4 \#$ \\
\hline Fuel & $\begin{array}{c}\text { Natural } \\
\text { gas }\end{array}$ & $\begin{array}{c}\text { Natural } \\
\text { gas }\end{array}$ & $\begin{array}{c}\text { Natural } \\
\text { gas }\end{array}$ & $\begin{array}{c}\text { Natural } \\
\text { gas }\end{array}$ \\
\hline $\begin{array}{c}\text { Flue gas } \\
\left.\text { temperature[ }{ }^{\circ} \mathrm{C}\right]\end{array}$ & 257.2 & 147.8 & 329.7 & 153 \\
\hline Air excess ratio & 1.49 & 1.49 & 1.70 & 4.88 \\
\hline $\begin{array}{c}\text { exhaust gas loss[\%] } \\
\text { heat dissipation } \\
\text { loss[\%] }\end{array}$ & 13.77 & 9.8 & 20.41 & 24.06 \\
\hline $\begin{array}{c}\text { Positive balance } \\
\text { efficiency[\%] }\end{array}$ & 83.33 & 87.30 & 76.69 & 70.92 \\
\hline $\begin{array}{c}\text { Counter balance } \\
\text { efficiency[\%] }\end{array}$ & 83.43 & 86.34 & 77.05 & 70.97 \\
\hline
\end{tabular}

\section{MODELING AND MESHING}

Regarding one gas furnace as the research object, set up the simulation model. Radiation chamber is a cylinder with diameter of $11.7 \mathrm{~m}$, height of $21.5 \mathrm{~m}$; Convection chamber is a rectangle with length of $7.7 \mathrm{~m}$, width of $3.2 \mathrm{~m}$ and 10.6 $\mathrm{m}$ height. Chimney is a cylinder too, with diameter of $2.7 \mathrm{~m}$, height of $25.2 \mathrm{~m}$. 12 combustor distribute uniformly at the bottom of the furnace which have a distance of $3.5 \mathrm{~m}$ from the center of the combustion chamber. Fig.1 shows the geometric model of this furnace.

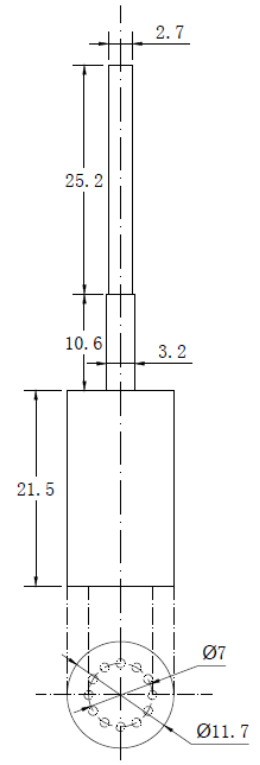

Fig.1. The geometric model of furnace

Computational domain consists of the whole radiation chamber and the outlet of the combustion. While meshing, structured grid was adopted in main computational area, and unstructured grid was used in the combining site of the combustion and furnace.

\section{Selection Of CAlculation Model AND BOUNDARY CONDITIONS}

In this paper, gas combustion basic equations were used, including continuity equation, momentum equation, energy equation and component transport equation, etc. Fuel jet into the furnace through the combustor nozzle with the flow regime of turbulence, so Reynolds average control equations of turbulence was selected. At the same time, standard $k-\varepsilon$ turbulence model, EDC combustion model, DO radiation model and the generating model of thermal and prompt $\mathrm{NO}_{\mathrm{x}}$ model were also used.

Velocity inlet and pressure outlet boundary conditions were selected; during the operational process of the steam-inject boiler, the mass flow rate of fuel inlet was determined by $0.83 \mathrm{~kg} / \mathrm{s}$, and its temperature was $348 \mathrm{~K}$; air inlet mass flow rate was $1.86 \mathrm{~kg} / \mathrm{s}$ (air excess ratio was 1.15 ), with temperature of $468 \mathrm{~K}$. Constant temperature solid wall conditions were used in radiation chamber and convection chamber; other walls used adiabatic conditions.

\section{IMPACT OF AIR EXCESS RATIO ON THE PERFORMANCE OF FURNACE}

\section{A. Impact on the temperature distribution in the furnace}

In the operational process of furnace, air excess ratio would affect the oxygen concentration and the combustion rate in the furnace, and then change the temperature field distribution in the furnace. High air excess ratio could provide enough oxygen concentration required by reaction to uniform the temperature field in the furnace though, it also would take more cold air into the furnace chamber, which might lower the temperature in the furnace. Therefore, it is extremely important to explore the variation of the air excess ratio and temperature field distribution.

Taking 5 groups of air excess ratio from 1.0 to 1.2 and making comparative analysis of numerical simulation, as Fig.2 shows that when the air excess ratio increased from 1.0 to 1.05 , the temperature distribution in the furnace was more uniform. This shows that the increase of air output accelerated the mixing of fuel and air, so as to make the combustion more intense and completely. When air excess ratio increased from 1.05 to 1.2 gradually, the flame temperature and the furnace temperature presented obvious decrease trend, which illustrated that the effect to the improvement of combustion by the increase of oxygen concentration had been weakening. Thus, excessive cold air was lowering the furnace temperature by heat transformation. In consequence, the temperature field distribution is the most uniform at the air excess ratio of 1.05 , and the combustion condition is the most ideal at this time. 


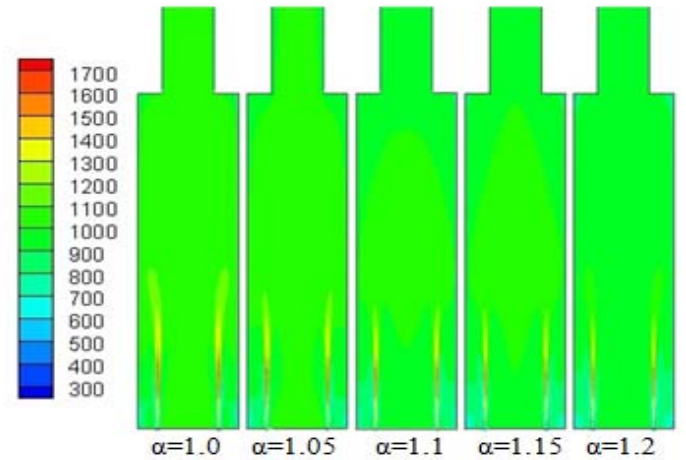

Fig.2. The impact of air excess ratio on temperature distribution(K)

\section{B. Impact on thermal efficiency}

Fig. 3 is for the impact of air excess ratio on the thermal efficiency of furnace. The figure shows that when the air excess ratio changed in the range of 1.0 1.05, thermal efficiency increased with the rise of air excess ratio. The peak of curve appeared at the air excess ratio of 1.05 , the thermal efficiency reached the maximum of $90.55 \%$. This accounts for that with the increase of air excess ratio, the amount of oxygen flux increased constantly, which accelerated the combustion rate. As a result, the temperature distribution was more uniform and thermal efficiency was higher. Flame in the furnace was burning sufficiently most at the peak value, and the radiation heat transfer was high at this point, so as to ensure a high thermal efficiency. After the air excess ratio exceeded 1.05, temperature in the furnace decreased because of the inlet flow of cold air. At the same time, air and nitrogen which was not involved in the reaction discharged directly in the form of flue gas, carrying a great quantity of heat and causing more heat loss. Therefore, the higher air excess ratio is, the lower thermal efficiency is.

During the normal operational process of the furnace, as a result of the operation staff on site do not familiar with the details and reaction mechanism of the combustion process, when appearing low thermal efficiency and short flame, the staff often operate relying on experiences. Thus, there is no scientific and unified standard which can provide safety indicators for the improvement of combustion and the control of air excess ratio. By the analysis of simulation calculation, the result could provide the operation staff on site the effect of air excess ratio to temperature and thermal efficiency. It can explain the problems occurred during the running time of the furnace, and then give theoretical basis for optimizing the performance of the furnace.

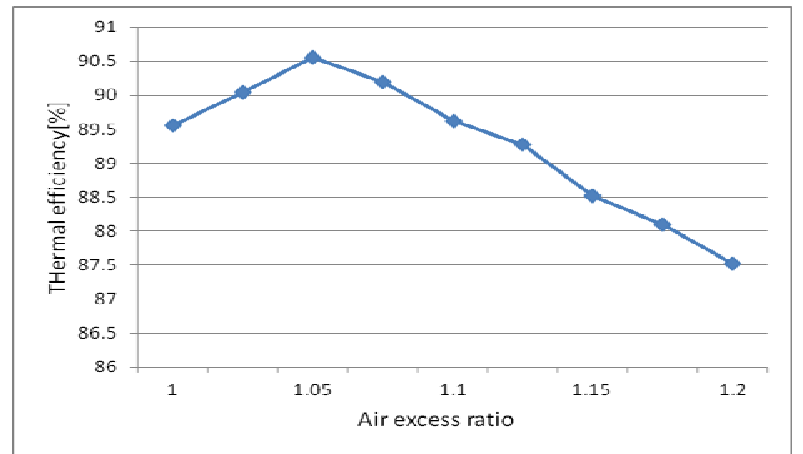

Fig.3. The impact of air excess ratio on the thermal efficiency

\section{Impact on NOx generation}

Air excess ratio affects the temperature distribution and the oxygen concentration in the furnace directly, while temperature and oxygen concentration have vital influence on $\mathrm{NO}_{\mathrm{x}}$ generation. For this reason, studying the relationship between air excess ratio and $\mathrm{NO}_{\mathrm{x}}$ generation has very important significance to the energy conservation and emissions reduction of tube furnace.

Taking 5 groups of air excess ratio from 1.0 to 1.2 and making comparative analysis of numerical simulation about $\mathrm{NO}_{\mathrm{x}}$ generation. As shows in Fig.4, when air excess ratio was less than 1.05 , in the wake of air excess ratio increasing, the $\mathrm{NO}_{\mathrm{x}}$ concentration rose obviously. It shows that with the air excess ratio's rise, the oxygen flowed into the boiler more, which accelerated the $\mathrm{NO}_{\mathrm{x}}$ generation rate. But when air excess ratio exceeded 1.05, NOx concentration dropped along with the ratio increased. This illustrates that excessive cold air flowed into the furnace and reduced the temperature in the furnace. Although the oxygen concentration increased, the $\mathrm{NO}_{\mathrm{x}}$ reaction was restrained by the effect of the temperature drop, which made the $\mathrm{NO}_{\mathrm{x}}$ concentration lessened following the air excess ratio's drop. When air excess ratio was 1.05 , the $\mathrm{NO}_{\mathrm{x}}$ generation reached the top.

Considering the require of efficiency and emission reduction of this furnace, the conclusion was made that when the air excess ratio was 1.05 , the furnace reached the optimum conditions. At this time, the temperature field distribution and combustion status were the most ideal, and the thermal efficiency also achieved the optimal of $90.55 \%$. But the $\mathrm{NO}_{\mathrm{x}}$ generation was the largest as well, thus it is necessary to combine on-site conditions and national standards to adjust the air excess ratio of furnace. 


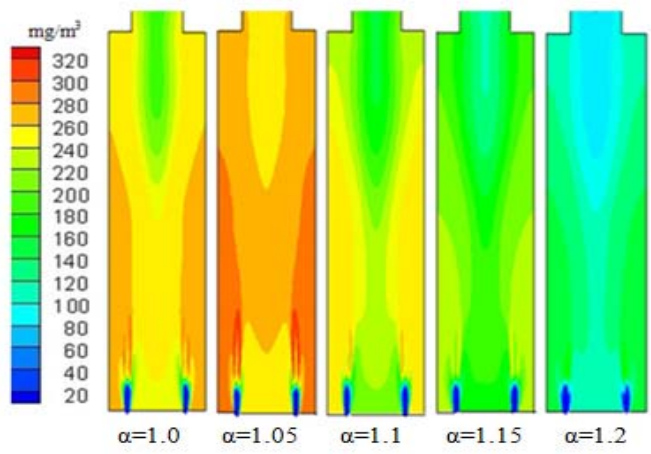

Fig.4. The impact of air excess ratio on NOx concentration distribution

\section{IMPACT OF FLUE GAS TEMPERATURE ON THE PERFORMANCE OF FURNACE}

According to the results of on-site measurement, in the actual operational process of furnace, the flue gas temperature of oil-fired furnace is $227.5^{\circ} \mathrm{C}$ on average, while the natural-gas-fired furnace is $190.35^{\circ} \mathrm{C}$. Consulting the limit value of $\leq 160^{\circ} \mathrm{C}$ in the standard, average flue gas temperature's percent of pass is only $60 \%$, which leads to the higher heat loss and lower thermal efficiency. Fig. 5 shows the impact of flue gas temperature on the thermal efficiency. It can be seen that thermal efficiency decreases linearly approximately along with the rise of flue gas temperature.

Reducing the flue gas temperature is one of the effective ways to reduce the production cost and thermal efficiency of the furnace, it can distinctly promote the improvement of waste heat recovery and reduction of heat loss. But if the flue gas temperature is too low, some liquefaction pollutants and dusts in the exhaust gas would attach on the heat exchanger and furnace tube, which would lead to corrosion or burn-through of heating surface. Therefore, flue gas temperature should not be too low; generally, $130^{\circ} \mathrm{C}$ is the best.

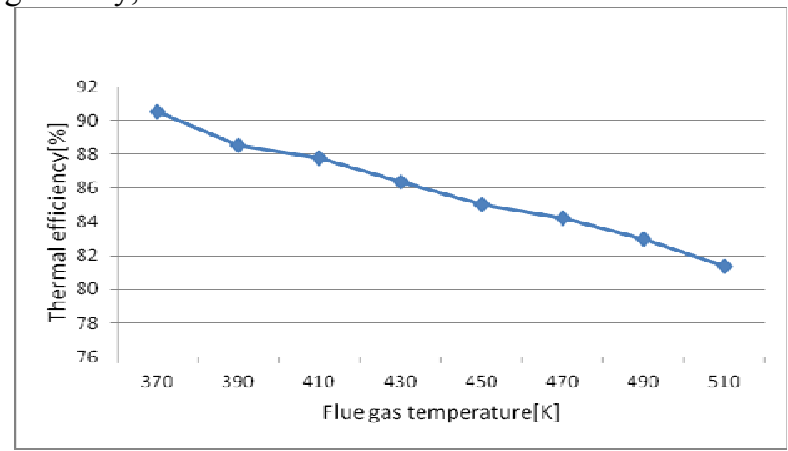

Fig.5. The impact of flue gas temperature on the thermal efficiency

\section{IMPACT OF EMISSIVITY ON THE PERFORMANCE OF FURNACE}

After running a period of time, the furnace lining is usually prone to gather dust or be aging and peel off, that will destroy the original materials of lining and lessen the emissivity of furnace lining. As a result, the heat loss will rise and affect the radiative transfer and heat preservation. Therefore, it is quite significant for the operational status of furnace to keep the emissivity in a reasonable range. The emissivity of firebricks in room temperature is $0.5 \sim 0.7$, and it declines with the rise of furnace temperature. When the temperature reached 1000 1300K, firebricks' emissivity was only 0.5 ; and when temperature came to $1600 \mathrm{~K}$, the emissivity would drop to 0.4 approximately. Employing high emissivity materials is an effective way to improve the emissivity of furnace lining to 0.9 . Consequently, improving the emissivity of furnace lining can be an important way to improve the thermal efficiency.[3-6] This time, the relationship between the emissivity of furnace lining and thermal efficiency were simulated. Fig. 6 illustrates the impact of emissivity to thermal efficiency. According to the calculation result, when the emissivity was less than 0.4 , thermal efficiency increased approximately linearly along with the rise of emissivity; And after the emissivity being greater than 0.4 , in the wake of the increase of emissivity, the rising trend of thermal efficiency had been slow down.

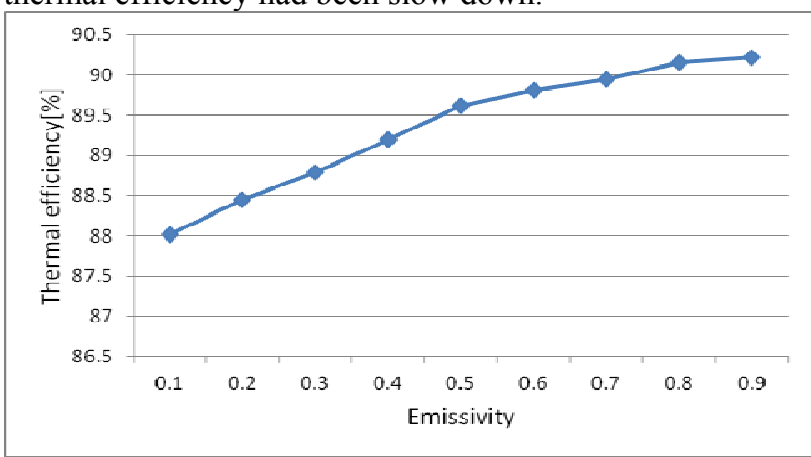

Fig.6. The impact of emissivity on the thermal efficiency

Improving the emissivity can reduce the heat loss of furnace wall, strengthen the radiation transfer, adjust the direction of the heat rays and perfect the uniformity of furnace temperature. But it only improves the reflection of furnace wall and reflect the heat to furnace. The improvement of emissivity can not make the furnace lining to be a heat source to provide heat. Therefore, the impact of emissivity on thermal efficiency is limited.

\section{CONCLUSION}

By researching the influence of air excess ratio to boiler temperature, thermal efficiency and $\mathrm{NO}_{\mathrm{x}}$ generation, the conclusion was made that while other conditions were constant and only air excess ratio changed in the range of $1.0 \sim 1.05$, thermal efficiency and $\mathrm{NO}_{\mathrm{x}}$ generation increased along with the rise of air excess ratio; thermal efficiency and $\mathrm{NO}_{\mathrm{x}}$ generation reached the top at the air excess ratio of 1.05; When air excess ratio changed in 1.05 1.2, with the increase of air excess ratio, the thermal efficiency and $\mathrm{NO}_{\mathrm{x}}$ production were reducing gradually.

By studying the impact of flue gas temperature on the thermal efficiency of furnace, it is showed that with the increase of flue gas temperature, the thermal efficiency 
decreases linearly approximately; But under the influence of corrosion in low temperature, flue gas temperature should not be too low, $130^{\circ} \mathrm{C}$ is preferred.

The emissivity of furnace lining is one of the main factors infuluencing the status of furnace, and it affects the thermal efficiency by the way of changing the furnace radiation effect. The results show that when the emissivity was less than 0.4, thermal efficiency increased approximately linearly along with the rise of emissivity; And after the emissivity being greater than 0.4 , in the wake of the increase of emissivity, the rising trend of thermal efficiency had been slow down.

\section{REFERENCES}

[1] Jin Shiping, Su Hongxing, Chen Weihan, et al. Energy saving technology for tubula-furnace through awirl flow field combustion. J. Huazhong Univ. of Sci. \& Tch. (Nature Science Edition) 2005, 33(5):76-79.

[2] OU Jianping, WU Daohong, XIAO Zeqiang. Numerical simulation on the flow, combustion and heat transfer in regenerative reheating furnace. Industrial Furnace, 2003, 5(1): 52-54.

[3] Dan Zhigang, Cang Daqiang, Zhou Huimin. Fabrication and performance of high-emissivity, energy-saving coating. J. of Wuhan Uni. of Sci.\& Tech.(Natural Science Edition),2007,30(6):561-563.

[4] WU Defei, MAO Yu, JIANG Hua, et al. three-dimensional numerical simulation of turbulent flow and combustion in gas burner with complicated structure, 2003,27(2):93-97.

[5] NIE Yuqiang, KUANG Xiaolei, Design and improving of direct-heating type environment protection hot-blast furnace. Industrial Furnace, 2006,4(2): 15-17.

[6] CUI Miao, CHEN Haigeng, CHEN Yu, WU Bin, Study on emissivities and absorptivities of gas in reheating furnace. Journal of Northeastern University(Natural Science),2008,29(1):97-100. 